\title{
Feasibility study for downscaling seasonal tropical cyclone activity using the NCEP regional spectral model
}

\author{
Suzana J. Camargo, * Huilan Li and Liqiang Sun \\ International Research Institute for Climate and Society, The Earth Institute at Columbia University, Lamont Campus, Palisades, NY, USA
}

\begin{abstract}
:
The potential use of the National Centers for Environmental Prediction (NCEP) Regional Spectral Model (RSM) for downscaling seasonal tropical cyclone (TC) activity was analyzed here. The NCEP RSM with horizontal resolution of $50 \mathrm{~km}$, was used to downscale the ECHAM4.5 Atmospheric General Circulation Model (AGCM) simulations forced with observed sea surface temperature (SST) over the western North Pacific. An ensemble of ten runs for June-November 1994 and 1998 was studied. The representation of the TCs is much improved compared to the low-resolution forcing AGCM, but the TCs are not as intense as observed ones, as the RSM horizontal resolution is not sufficiently high. The large-scale fields of the RSM are examined and compared to both the AGCM and the European Centre for Medium-Range Weather Forecasts (ECMWF) reanalysis. The large-scale fields of RSM characteristics are in general similar to those of the reanalysis. Various properties of the TCs in the RSM are also examined such as first positions, tracks, accumulated cyclone energy (ACE) and duration. While the RSM does not reproduce the higher number of TCs in 1994 than in 1998 , other measures of TC activity (ACE, number of cyclone days) in the RSM are higher in 1994 than in 1998. Copyright (C) 2006 Royal Meteorological Society
\end{abstract}

KEY WORDS tropical cyclones; typhoons; regional climate models; seasonal forecasts; western North Pacific

Received 20 December 2005; Revised 6 July 2006; Accepted 7 July 2006

\section{INTRODUCTION}

The western North Pacific is the basin with most tropical cyclone (TC) activity. Severe TCs or typhoons are a significant natural hazard for many Asian countries such as Japan, China, Philippines and Vietnam, making forecasting of seasonal tropical typhoon activity an important task. Operational forecasts (statistical and dynamical) of seasonal typhoon activity are currently available from: City University of Hong Kong (Chan et al., 1998, 2001; Liu and Chan, 2003), Tropical Storm Risk (TSR, 2006), IRI - International Research Institute for Climate and Society (IRI, 2006), ECMWF - European Center for Medium-Range Weather Forecasts (Vitart and Stockdale, 2001b; Vitart et al., 2003; Vitart, 2006). In this work, we are interested in examining the potential use of regional climate models in forecasting seasonal TC activity in the western North Pacific.

Many studies have analyzed the properties of cyclonelike structures in Atmospheric General Circulation Models (AGCMs), finding that the simulated TCs have properties similar to those of observed TCs (Manabe et al., 1970; Bengtsson et al., 1982; Broccoli and Manabe, 1990; Wu and Lau, 1992; Haarsma et al., 1993; Bengtsson et al., 1995; Tsutsui and Kasahara, 1996; Vitart

* Correspondence to: Suzana J. Camargo, IRI, Monell 225, 61 Route 9W, Palisades, NY 10964-8000, USA.

E-mail: suzana@iri.columbia.edu et al., 1997, 1999; Camargo and Sobel, 2004; Camargo et al., 2005). General circulation climate models have also been extensively used to study the influence of greenhouse gases on TC activity (Broccoli and Manabe, 1990; Ryan et al., 1992; Haarsma et al., 1993; Bengtsson et al., 1996; Royer et al., 1998; Druyan et al., 1999; Walsh and Ryan, 2000; Sugi et al., 2002; Walsh et al., 2004; Knutson and Tuleya, 2004; Walsh, 2004). Other climate influences on TCs, such as El Niño-Southern Oscillation (ENSO) and decadal variability, have been explored using both AGCMs (Wu and Lau, 1992; Vitart et al., 1997, 1999; Vitart and Anderson, 2001a) and coupled atmosphere-ocean models (Matsuura et al., 1999, 2003; Yumoto et al., 2003; Vitart et al., 2003). However, the modeled TCs have deficiencies related to the relatively low resolution of the models. In particular the model TCs tend to lack a distinct eye, eye wall and rain bands and have a larger horizontal scale than observed. The importance of high resolution for the realistic description of TCs is well-known (Kobayashi and Sugi, 2004), and resolution is at least one of the major reasons why lowresolution global reanalysis products do not describe TC activity well (Serrano, 1997; Fiorino, 2002; Cheung and Elsberry, 2002).

Dynamical downscaling using a regional model is a computationally efficient means of increasing the AGCM resolution in a limited area. In this approach, the regional climate model is forced by low-resolution fields from 
the AGCM. This method has been used in many problems, including seasonal precipitation forecasts over the northeast of Brazil (Sun et al., 2005, 2006). The purpose of this work is to investigate whether the higher resolution of the regional model could improve upon the skill of the AGCM to simulate seasonal TC activity. The AGCM used here is the ECHAM4.5 developed at the Max-Planck Institute for Meteorology in Hamburg (Roeckner et al., 1996). This model has been studied extensively in various aspects of seasonal TCs activity (Camargo and Zebiak, 2002; Camargo and Sobel, 2004; Camargo et al., 2005) and is currently used operationally for experimental dynamical seasonal forecasts of TCs (IRI, 2006). The regional model used is the Regional Spectral Model (RSM) developed at National Centers for Environmental Prediction (NCEP) (Juang and Kanamitsu, 1994; Juang et al., 1997; Juang and Hong, 2001). The dynamical downscaling is performed in the western North Pacific, where $30 \%$ of the global TC activity occurs and where typhoons have important societal impacts.

Previous studies have looked at the ability of regional models to represent TCs using reanalysis forcing (Landman et al., 2005) and AGCM forcing (greenhouse gases effects on TC activity over the Australian region; Walsh, 1997; Walsh and Ryan, 2000; Nguyen and Walsh, 2001; Walsh and Syktus, 2003; Walsh et al., 2004). Our aim here is to determine how successfully regional models can be used in operational settings to simulate the variability of seasonal TC activity. Recently, an inter-comparison of regional climate models over the Asian region results was discussed (Fu et al., 2005), but the domain of that study is focused over the Asian continent and the RSM is not one of the regional models included in the project. In other recent downscaling studies the focus was to simulate the summer monsoon over China (Chan et al., 2004; Liu et al., 2006). One important issue that is also briefly discussed here is the influence of the choice of domain boundary on the regional climate model simulations (Seth and Giorgi, 1998; Landman et al., 2005; Rauscher et al., 2006).

The long-term goal of this study is to use a regional climate model to understand regional scale details of seasonal TC activity variability on seasonal and longer time scales. First, the basic properties of TCs simulated in the dynamical downscaling framework have to be studied, as well as the simulated regional circulation. With this aim, a few questions will be addressed here. The first question is: how well does the RSM represent typhoons, and does it improve upon the low-resolution AGCM? The second question is whether the RSM is able to independently form TCs in its domain, or whether it only provides more details about the TCs already present in the AGCM. The third (related to the second) is the performance of the RSM in simulating seasonal statistics of cyclones (typhoon number, intensity, tracks, interannual variability and genesis location).

In a recent paper, Castro et al. (2005) discuss the value added by dynamical downscaling to an AGCM. They concluded that surface boundary forcing is the dominant factor in generating atmospheric variability for smallscale features and that it exerts greater control on the regional model solution as the influence of the boundary conditions diminish. In their analysis, the value added by the regional model is to resolve small-scale features that have a greater dependence on the surface boundary. As a possible solution for these issues, spectral nudging is suggested in Castro et al. (2005). The regional model used in this study (RSM) is a spectral model, which is a procedure similar to the spectral nudging.

In Section 2, we describe the numerical experiment in this study. In Section 3 the sea surface temperature (SST) and atmospheric conditions associated with the TCs in the two seasons considered are discussed. In Section 4 the RSM TC activity characteristics are discussed. In Section 5 sensitivity tests for domain choice are discussed and the conclusions are given in Section 6.

\section{EXPERIMENT DESCRIPTION}

The ECHAM4.5 AGCM was configured at triangular 42 (T42) spectral truncation, giving a spatial resolution of about 2.8 degrees latitude-longitude, with 19 vertical layers (Roeckner et al., 1996). Multi-decadal ensemble simulations of approximately 50 years, forced by observed SST (Reynolds and Smith, 1994; Reynolds et al., 2002), have been produced by the ECHAM4.5 AGCM. The different ensemble members are generated by having slightly different initial states, obtained by perturbing a set of self-consistent model fields from a previous integration of this model. The NCEP RSM (Juang and Kanamitsu, 1994; Juang et al., 1997; Juang and Hong, 2001) with a horizontal resolution of $50 \mathrm{~km}$ is used to downscale ECHAM4.5 simulations over the western North Pacific. The regional model domain is $109.7^{\circ} \mathrm{E}$ to $162.6^{\circ} \mathrm{W}$, and $1.2^{\circ} \mathrm{N}$ to $42.1^{\circ} \mathrm{N}$, as shown in Figure 1 .

The one-way nesting of the NCEP RSM into the ECHAM4.5 AGCM is different from conventional methods, which only use global model fields along the lateral boundary zone. The perturbation nesting method uses the global model output over the entire regional domain, not just in the lateral boundary zone. The dependent variables in the regional domain are defined as a sum of a perturbation and a base. The base is a time dependent field from the AGCM. Variability resolved by the RSM in the regional domain is defined as the perturbation. The nesting is done in such a way that the perturbation is nonzero inside the domain but zero outside the domain. Five prognostic variables from the global model outputs are used as the base fields in the RSM. They are zonal and meridional winds, temperature, humidity and surface pressure. Perturbations are often concentrated in the smaller spatial scales. In some cases, the perturbations can be strong at larger spatial scales as well (e.g. Sun et al., 2006). All diagnostic variables (e.g. precipitation) are generated by the regional model itself. This spectral downscaling process is very similar to the spectral nudging discussed in Castro et al. (2005). 


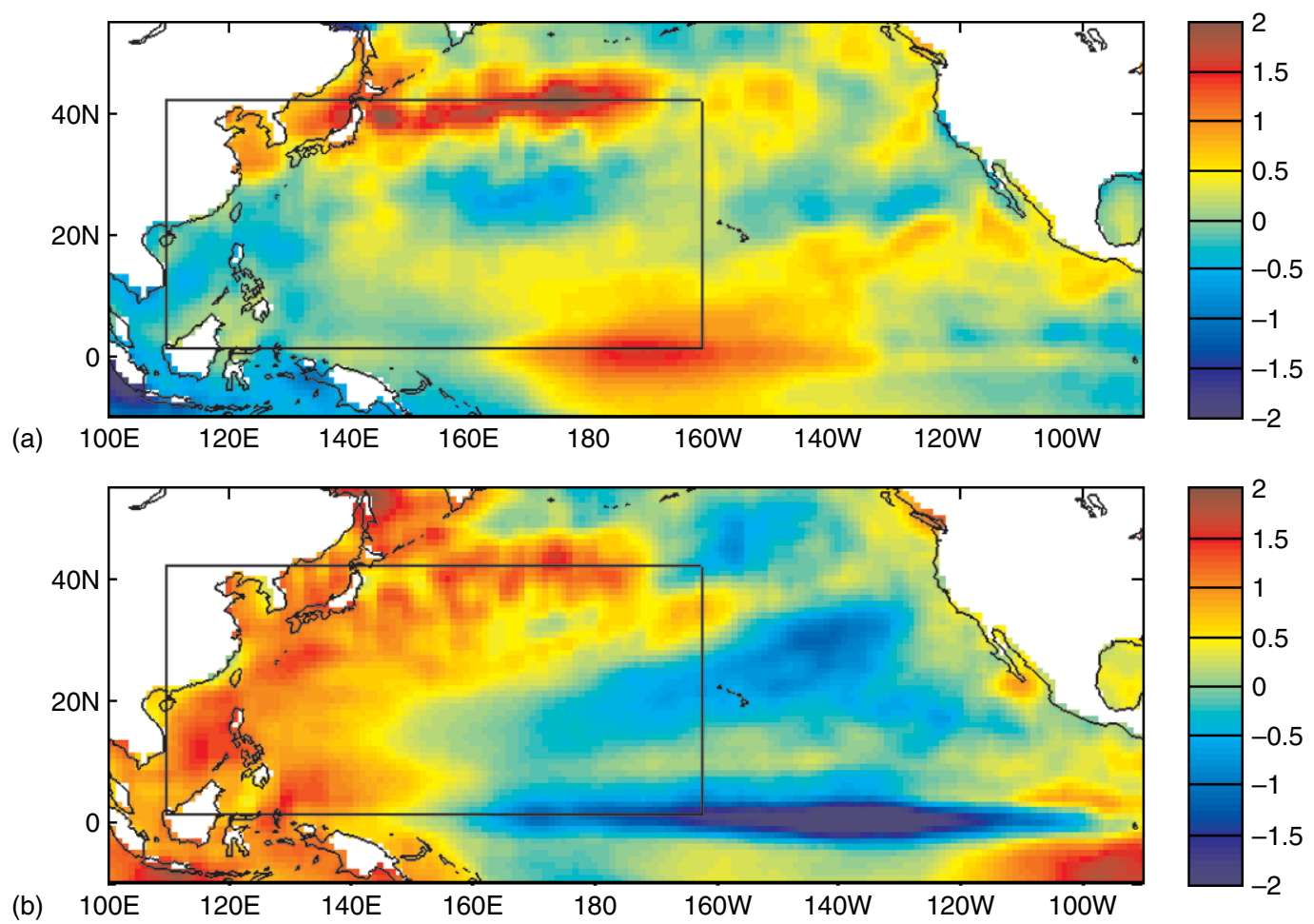

Figure 1. Observed mean sea surface temperature anomalies (in ${ }^{\circ}$ C) in the period June-November 1994 (a) and 1998 (b). The domain used for the regional spectral model simulations is also shown in both panels.

The peak of the typhoon activity in the western North Pacific is July to October, though typhoons do occur in any month of the year as shown in Figure 2(b). We chose the period June to November, of 1994 and 1998 to use the RSM to downscale the ECHAM4.5 AGCM simulations. For each year, we used ten ensemble members of the ECHAM4.5 simulation, creating an ensemble of ten integrations of the RSM for each year.

The ECHAM4.5 has a reasonable TC climatology over the western North Pacific, underestimates the number of typhoons in the peak season (July-October), a common characteristic in low-resolution AGCMs (Camargo et al., 2004a). The ECHAM4.5 has significant skill in simulating the interannual variability of the number of tropical storms and TCs in the western North Pacific (Camargo et al., 2004a, 2005). However, ECHAM4.5 does not reproduce years with extreme numbers of named tropical storms. For this reason, we chose for this experiment 2 years with extreme numbers of named tropical cyclones (NTC): 1994 (high activity) and 1998 (low activity), as shown in Figure 2(a). The ECHAM4.5 does produce few TCs in the western North Pacific in 1998, but does not produce enough in 1994. One of the questions is whether the RSM can increase the number of simulated TCs in such a year. It was noticed that the analysis of the ECHAM4.5 by Camargo et al. (2004a, 2005 ) used 24 ensemble members while here only 10 ensemble members are used to force the RSM, because of computational resources constraints.

To define and track TCs in the models, we used objective algorithms (Camargo and Zebiak, 2002) based on prior studies (Vitart et al., 1997; Bengtsson et al., 1995).
Table I. Thresholds for vorticity $(850 \mathrm{hPa})$, surface wind speed and anomalous temperature $(700,500$ and $300 \mathrm{hPa})$ in the RSM and ECHAM4.5 (western North Pacific) models.

\begin{tabular}{lccc}
\hline Thresholds & $\begin{array}{c}\text { Vorticity } \\
\left(\mathrm{s}^{-1}\right)\end{array}$ & $\begin{array}{c}\text { Wind } \\
\text { speed }\left(\mathrm{m} \mathrm{s}^{-1}\right)\end{array}$ & $\begin{array}{c}\text { Anomalous } \\
\text { Temperature } \\
\left({ }^{\circ} \mathrm{C}\right)\end{array}$ \\
\hline RSM & $4.9 \times 10^{-5}$ & 14.1 & 1.2 \\
ECHAM & $3.4 \times 10^{-5}$ & 12.0 & 1.9 \\
\hline
\end{tabular}

The algorithm has two parts. In the detection part, storms that meet environmental and duration criteria are identified. A model TC is identified when chosen dynamical and thermodynamical variables exceed thresholds based on observed tropical storm climatology. Most studies (Bengtsson et al., 1982; Vitart et al., 1997) use a single set of threshold criteria globally; however, these do not take into account model biases and deficiencies. We use basin- and model-dependent threshold criteria, based on each model's climatology (for ECHAM4.5 and for the RSM) (Camargo and Zebiak, 2002). The threshold values for ECHAM4.5 in the western North Pacific and the RSM are given in Table I. In the tracking part, the tracks are obtained from the vorticity centroid, which defines the center of the TC, and relaxed criteria. The detection and tracking algorithms have been previously applied to a regional climate model forced by reanalysis data (Landman et al., 2005) and to various AGCMs (Camargo and Zebiak, 2002; Camargo and Sobel, 2004; Camargo et al., 2005). 

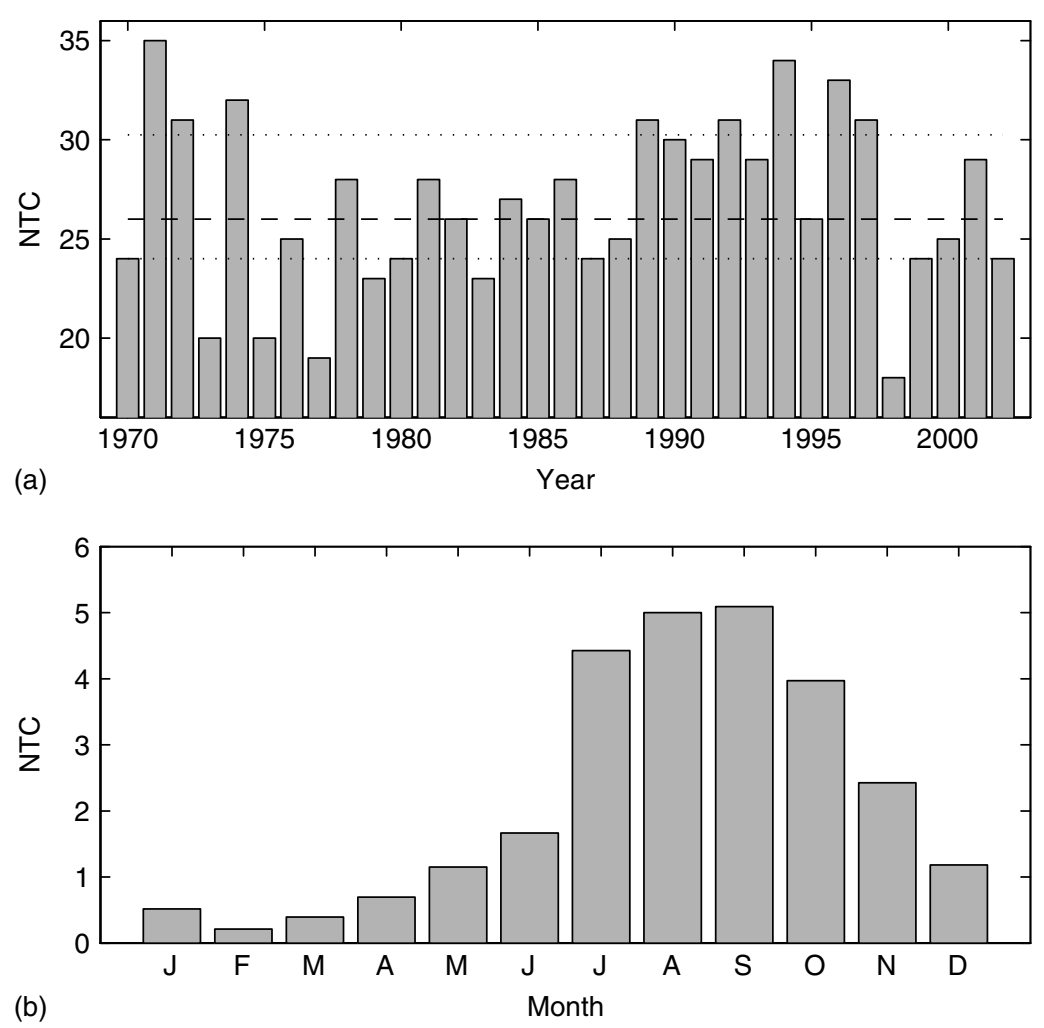

Figure 2. (a) Number of named tropical cyclones (NTC) per year, (b) average number of named tropical cyclones (NTC) per month in the western North Pacific in the period 1970-2002.

The TC observational data was based on the Typhoon Warning Center (JTWC) best track dataset for the years 1994 and 1998 (JTWC, 2006). Tropical depressions are present in the best track dataset, but here only TCs with tropical storm intensity or higher are included.

\section{OCEANIC AND ATMOSPHERIC CONDITIONS}

We begin by examining the SST and atmospheric conditions associated with TC formation for the two typhoon seasons studied. The SST anomalies, obtained from the Reynolds dataset (Reynolds et al., 2002), for JJASON (June-November) 1994 and 1998 are shown in Figure 1. In the summer and fall of 1994, the El Niño event of 1994/1995 was developing and positive SST anomalies in the central and eastern equatorial Pacific were observed. In contrast, in JJASON 1998, a long lasting La Niña event was developing, the SST in the Pacific warm pool were warmer than usual and negative SST anomalies in the central and eastern equatorial Pacific were evident. The western North Pacific SST anomalies were below normal (above normal) in 1994 (1998), associated with a high (low) number of typhoons. This association is consistent with the results of Chan and Liu (2004) and shows that in the western North Pacific the local SST does not determine the level of typhoon activity. Besides, there is an increase in the number of TCs in the western North Pacific during strong warm ENSO events (Wang and Chan, 2002). There is also a shift of TC activity to the southeast (northwest) in El Niño (La Niña) years (Pan,
1982; Chan, 1985; Chia and Ropelewski, 2002; Wang and Chan, 2002; Camargo et al., 2004b). This shift in TC genesis location in El Niño events leads to longer lived, more intense typhoons and therefore higher values of the accumulated cyclone energy (ACE) (Camargo and Sobel, 2005). A recent review of TC activity in the western North Pacific in interannual and interdecadal time scales is found in Chan (2005).

Besides SST, another important factor determining the amount of TC activity in a season is the vertical wind shear (i.e. the difference of the zonal winds at $200 \mathrm{hPa}$ and $850 \mathrm{hPa}$ ). Previous studies (Gray, 1979; McBride, 1981) show that a favorable environment for genesis of typhoons is such that the vertical wind shear should be minimal near the center of the TC but large away from the center. In McBride (1981), one of the requirements for genesis is the existence of a large positive zonal shear to the north and negative zonal shear close to the south of the developing system. Figure 3 shows the zonal wind shear for JJASON 1994 and 1998 for the models (ensemble mean) and the ECMWF reanalysis (Uppala et al., 2005). Both the RSM and the AGCM capture the overall pattern of the zonal wind shear in both years. In 1994 there is a much larger region favorable for development - low shear and positive (negative) shear to the north (south) - than in 1998.

The difference of the surface pressure between 1998 and 1994 is shown in Figure 4 for the RSM and ECHAM4.5 models and for the ECMWF reanalysis. In all cases, 1998 (low TC activity) has higher values of surface 

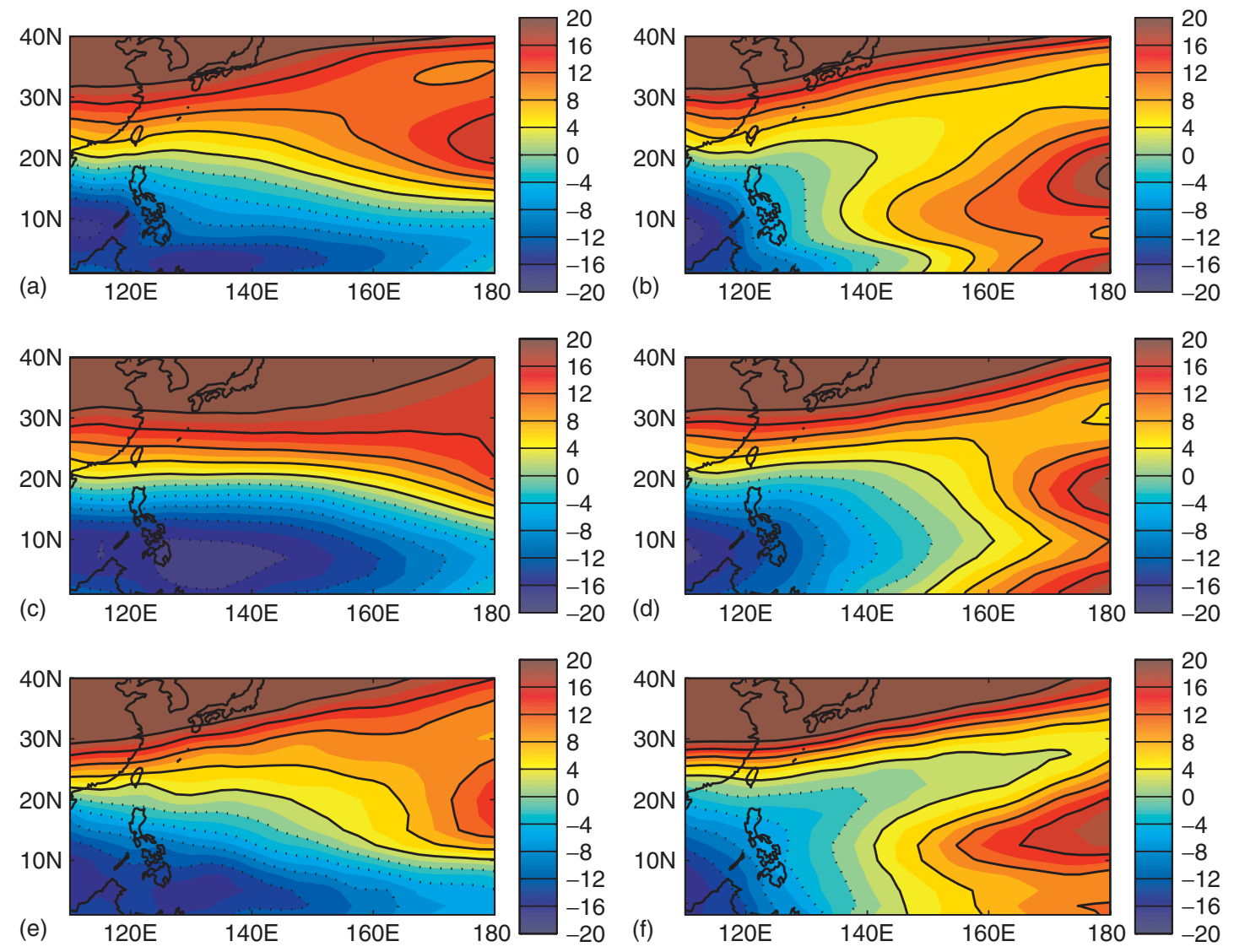

Figure 3. Vertical zonal wind shear (in $\mathrm{m} \mathrm{s}^{-1}$ ) of June-November 1994 (left panels) and 1998 (right panels) in the RSM ((a) and (b)), ECHAM4.5 ((c) and (d)) and ECMWF reanalysis ((e) and (f)). The vertical zonal wind shear is defined as the difference of the zonal winds between 200 and $850 \mathrm{hPa}$.

pressure than in 1994, showing a stronger subtropical high in the Pacific in that year. However, the RSM has a larger area of low surface pressure in the tropics than does either ECHAM or ECMWF.

In the northern summer, monsoonal southwesterly winds extend eastward from the Asian subcontinent. These near-equatorial westerlies meet the central Pacific easterlies on a moist confluence zone that is conducive to convection and wave accumulation (Holland, 1995; Sobel and Bretherton, 1999) and the formation of TCs (Briegel and Frank, 1997; Lander, 1996; Ritchie and Holland, 1999). In Figure 5, the zonal winds at $850 \mathrm{hPa}$ are shown for the RSM and ECHAM4.5 modes and the ECMWF reanalysis in 1994 and 1998. The monsoon trough region in 1994 extends to the eastern part of the western North Pacific region, contributing to the high TC activity in that year. In contrast, the westerlies in 1998 only reached the Philippines region, leading to a much smaller region of confluence in the Pacific. The RSM zonal winds are very similar to the reanalysis in both years, with the exception of stronger westerlies around $110^{\circ} \mathrm{E}$.

One of the factors important in the formation of TCs is the presence of cyclonic vorticity in lower levels. The vorticity at $850 \mathrm{hPa}$ for 1994 and 1998 (not shown) shows larger values of cyclonic vorticity in 1994 than in 1998 in both models and observations. However, the patterns are quite distinct. While the RSM model has a maximum around $10^{\circ} \mathrm{N}$, from $150^{\circ} \mathrm{E}$ to $170^{\circ} \mathrm{E}$, the ECHAM4.5 maximum occurs northeast of the Philippines $\left(20^{\circ} \mathrm{N}, 135^{\circ} \mathrm{E}\right)$. The position of this vorticity maximum in the ECHAM4.5 model is similar to the maximum in the ECMWF reanalysis. However, neither model shows the vorticity maximum over the South China Sea, which is present in the Reanalysis.

\section{CHARACTERISTICS OF RSM TROPICAL CYCLONES}

\subsection{Typical RSM tropical cyclone}

A typical TC in the RSM and ECHAM4.5 models is shown in Figures 6 and 7, respectively. The instantaneous fields near a model TC are shown at the same time in the RSM and ECHAM4.5 models. Higher resolution leads to a much finer representation of the $850 \mathrm{hPa}$ vorticity in the RSM compared with the ECHAM4.5. Also, the vorticity reaches much larger values in the RSM. Instantaneous precipitation and humidity values are also larger in the regional model, and there appears to be a rain band that was not present in the AGCM simulation. The maximum wind speed values are higher in the RSM representation of the storm, and there is a clear minimum in the center of the storm, an attempt by the RSM to produce the storm's 'eye'. 


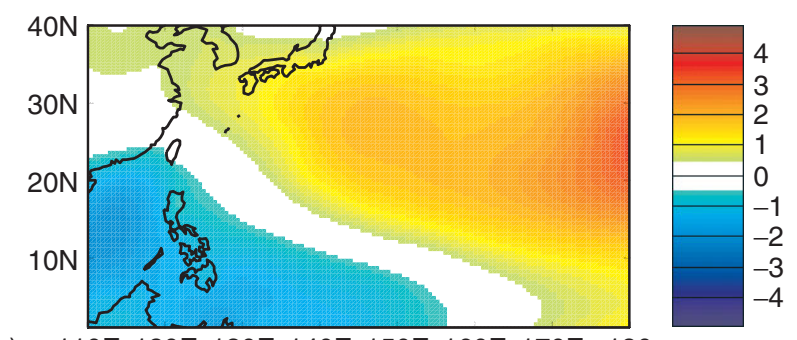

(a) 110E 120E 130E 140E 150E 160E 170E 180

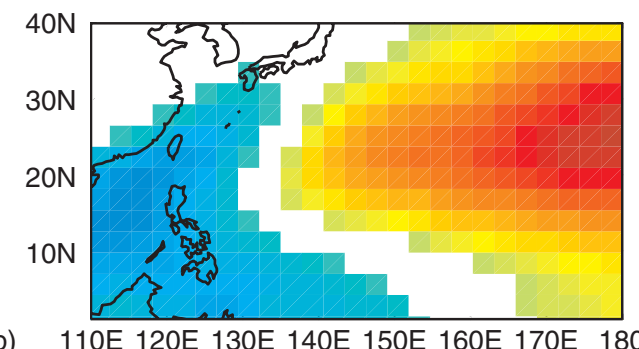

(b) 110E 120E 130E 140E 150E 160E 170E 180
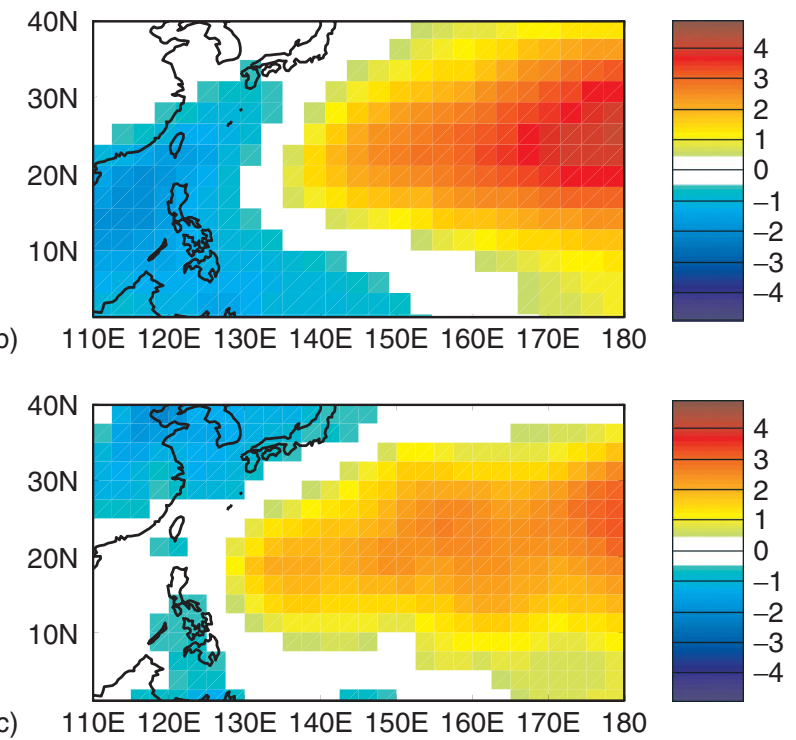

Figure 4. Surface pressure difference (in hPa) of JJASON 1998 and 1994 (a) RSM, (b) ECHAM4.5 and (c) ECMWF reanalysis.

Therefore, higher resolution gives a representation of the TC that is much more similar to reality than that obtained using a coarse resolution model. The next question to be answered is whether the higher resolution improves aspects of the model that are important for seasonal prediction of TC activity.

\subsection{Number of tropical cyclones}

In the 2 years chosen for our experiment, 1994 and 1998, there was a large difference in the number of NTCs in the observations in the period JJASON, namely 30 in 1994 and 16 in 1998. Table II shows the ensemble mean number of TCs in JJASON 1994 and 1998 for both models and the observations. The mean number of JJASON NTCs in the period 1970-2002 (more reliable data, postsatellite) in the western North Pacific is 22.6, and the standard deviation is 3.8. So both years have

Table II. Number of tropical cyclones per season (JJASON) in the models (ensemble mean) and observations in 1994 and 1998.

\begin{tabular}{lll}
\hline & 1994 & 1998 \\
\hline RSM & 36.3 & 39.3 \\
ECHAM4.5 & 18.3 & 13.9 \\
Observations & 30 & 16 \\
\hline
\end{tabular}

a number of TCs that differ from the historical mean by more than one standard deviation. In the period 1970-2002, 1998 had the lowest number of NTCs in the peak season (JJASON), while 1994 had the second highest, fewer only than 1971.

The mean number of JJASON TCs in the western North Pacific produced by the ECHAM4.5 using the average of 10 ensemble members in the period 1970-2002 is 16.8 (16.4 with 24 ensemble members), with a standard deviation of 1.7 (1.6 with 24 ensemble members). The ensemble mean number of TCs produced by ECHAM4.5 forced with observed SST (and 10 ensemble members) in JJASON 1994 and 1998 was, respectively, 18.3 and 13.9 (Table II), not as large a difference as in the observations, but the standard deviation is also lower. The difference between the ensemble mean number of TCs of ECHAM4.5 in both years is statistically significant at the 5\% level using both the Wilcoxon rank sun test for the median of two distributions and the two-sample $t$ test for the mean of two distributions. It is interesting that although the ECHAM4.5, which is forcing RSM has a bias toward a low number of TCs, the RSM has a bias in the opposite direction, with too many TCs (Table II). Another interesting aspect is that ECHAM4.5 has more TCs in 1994 than in 1998, as is the case of the observations. In contrast, the ensemble mean number of TCs for the RSM is larger in 1998 than in 1994.

\subsection{Tropical cyclones genesis locations}

One of the crucial questions is whether the RSM model forms TCs independent of the global model. As we saw in the previous section, the RSM has more TCs per season than the ECHAM4.5. This means that the RSM is able to create at least a few TCs on its own. Let us examine the TC genesis locations. Figure 8 shows the first position of all TCs in the observations and in one of the ensemble members of the models. Note the formation of cyclones near the Philippines in the RSM, which does not happen in the ECHAM4.5. The first position density (not shown), constructed using all ensemble members confirms the formation of TCs in the RSM that did not exist in the ECHAM4.5 model.

Regarding the distribution of the genesis location of the TCs (not shown), the westward bias of the ECHAM4.5 model (Camargo et al., 2004a, 2005) is also present in the RSM model; while the southward bias is partially corrected, probably because of the finer resolution. In the observations, the genesis occurs further west in 1994 than in 1998, a feature that is reproduced in the ECHAM4.5 model, but not as well by the RSM model. In 1998, the observed genesis latitudes had a much smaller standard deviation $\left(3.5^{\circ}\right)$ than in $1994\left(6.2^{\circ}\right)$. The ECHAM4.5 model latitude distribution in 1994 is shifted equatorward in comparison with 1998, but the standard deviation in both years is much more similar than in observations $\left(5.6^{\circ}\right)$ and $\left(5.2^{\circ}\right)$, respectively. 

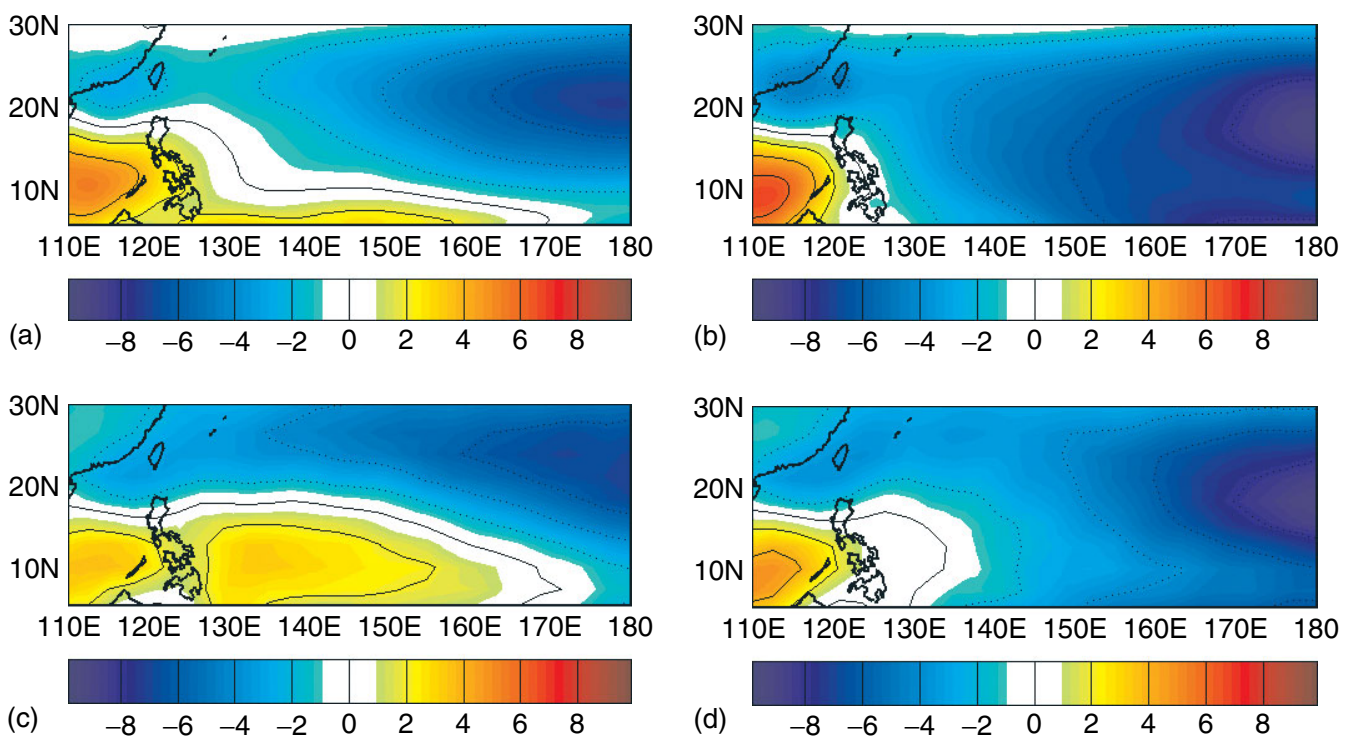

(c)
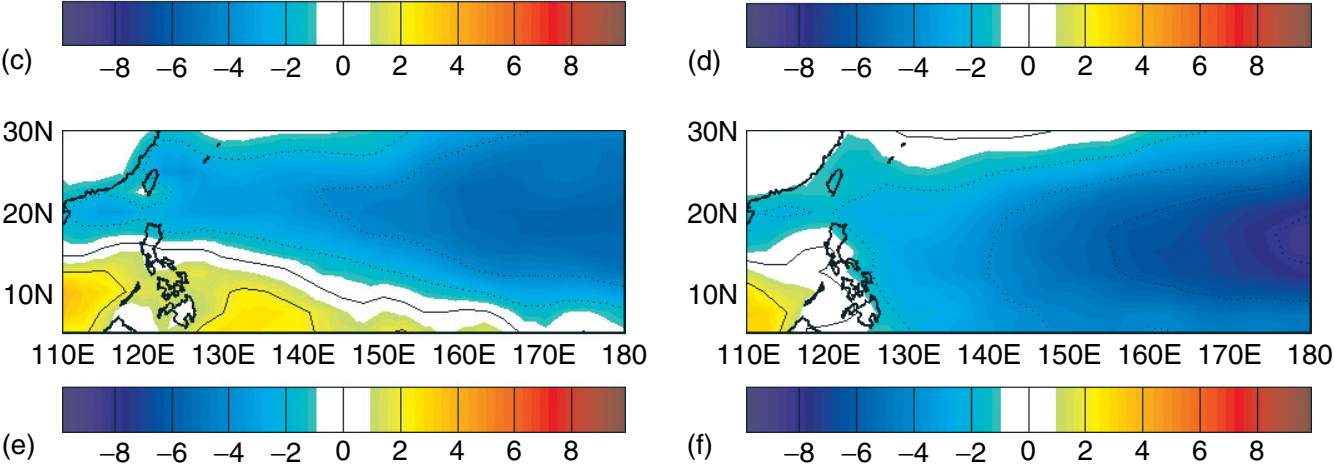

Figure 5. Zonal winds at $850 \mathrm{hPa}$ (in $\mathrm{m} \mathrm{s}^{-1}$ ) for the season June-November: in 1994 (left panels) and 1998 (right panels) for the RSM (a) and (b), ECHAM4.5 (c) and (d), ECMWF reanalysis (e) and (f).
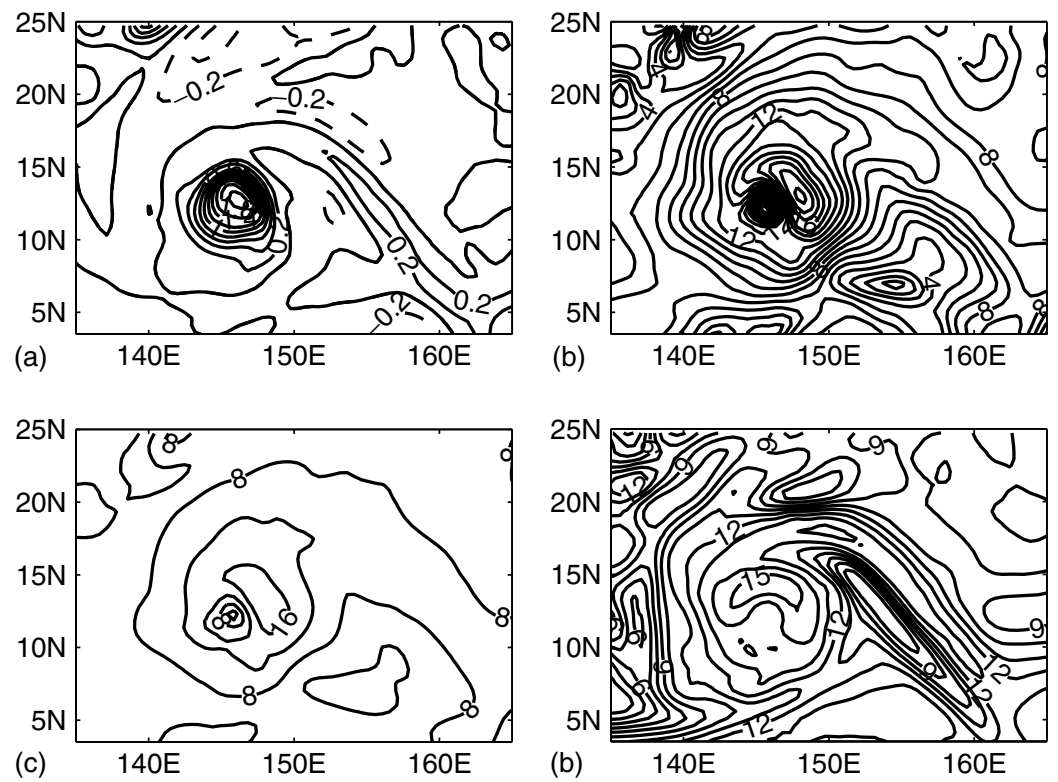

Figure 6. Typical fields of a RSM model tropical cyclone. (a) Vorticity at $850 \mathrm{hPa}\left(\times 10^{-4} \mathrm{~s}^{-1}\right)$, (b) wind speed at $1000 \mathrm{hPa}$ (m $\left.\mathrm{s}^{-1}\right)$, (c) precipitation $\left(\mathrm{mm} \mathrm{day}^{-1}\right)$ and (d) specific humidity $850 \mathrm{hPa}\left(\mathrm{g} \mathrm{kg}^{-1}\right)$, at 00:00 14 June 1994 in one of the ensemble members.

\subsection{Tracks}

Examining the tracks in the models and observations (Figure 9), we see that RSM has smoother tracks than does the ECHAM4.5, probably because of the higher resolution of RSM. However, the tracks still do not look very similar to the observed tracks, with very few TCs making landfall and with some TCs staying almost stationary for a few days, especially near the RSM boundaries. 

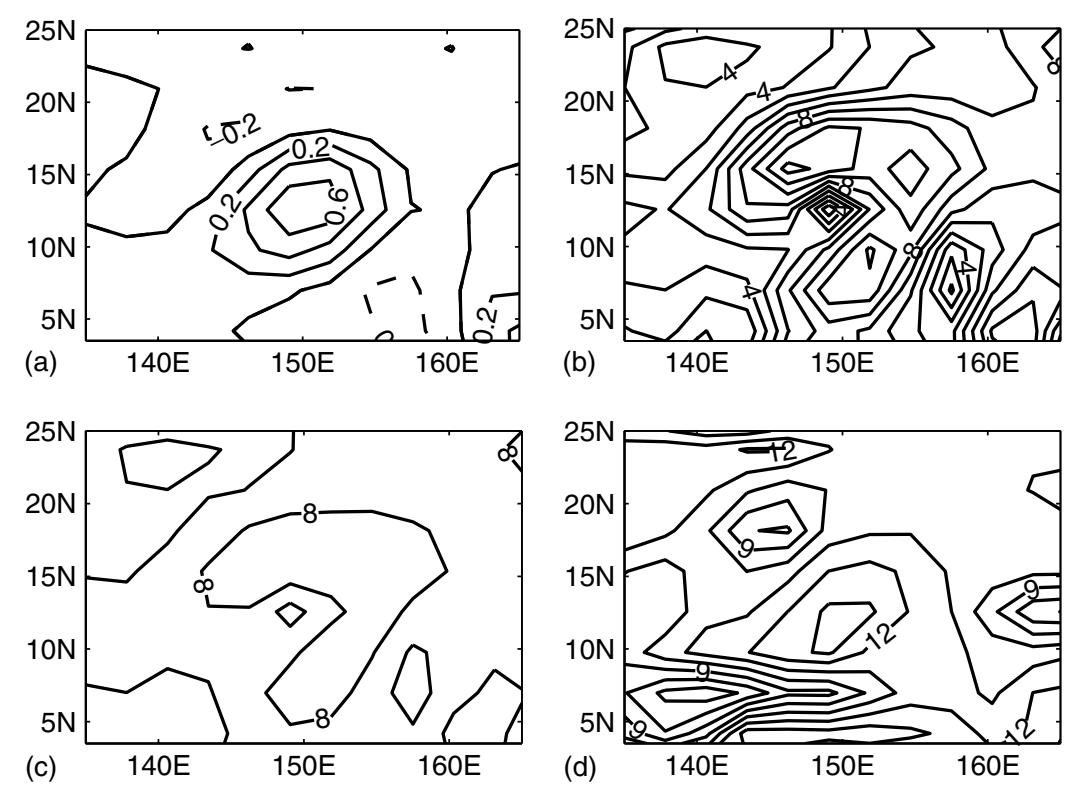

Figure 7. Typical fields of a ECHAM4.5 model tropical cyclone. (a) Vorticity at $850 \mathrm{hPa}\left(\times 10^{-4} \mathrm{~s}^{-1}\right)$, (b) wind speed at $1000 \mathrm{hPa}\left(\mathrm{m} \mathrm{s}^{-1}\right)$, (c) precipitation $\left(\mathrm{mm} \mathrm{day}^{-1}\right)$ and (d) specific humidity at $850 \mathrm{hPa}\left(\mathrm{g} \mathrm{kg}^{-1}\right)$, at 00:00 14 June 1994 in the ensemble member that forces the simulation of RSM shown in Figure 6.

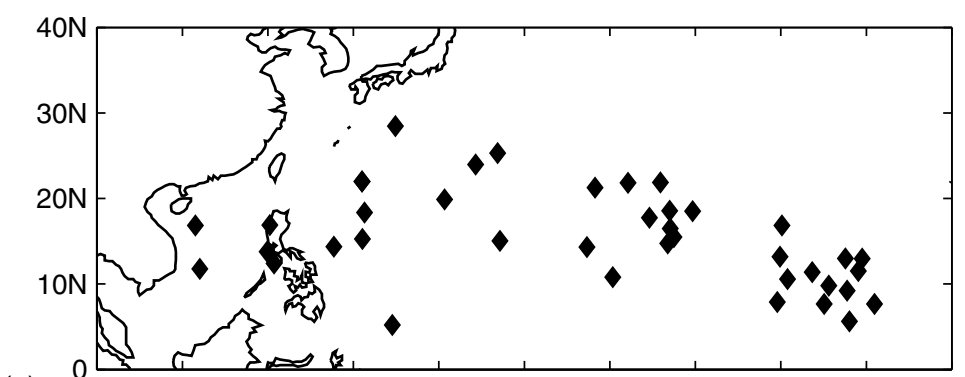

(a) 100E $110 \mathrm{E}$ 120E $130 \mathrm{E}$ 140E $150 \mathrm{E}$ 160E $170 \mathrm{E}$ 180 $170 \mathrm{~W}$ 160W
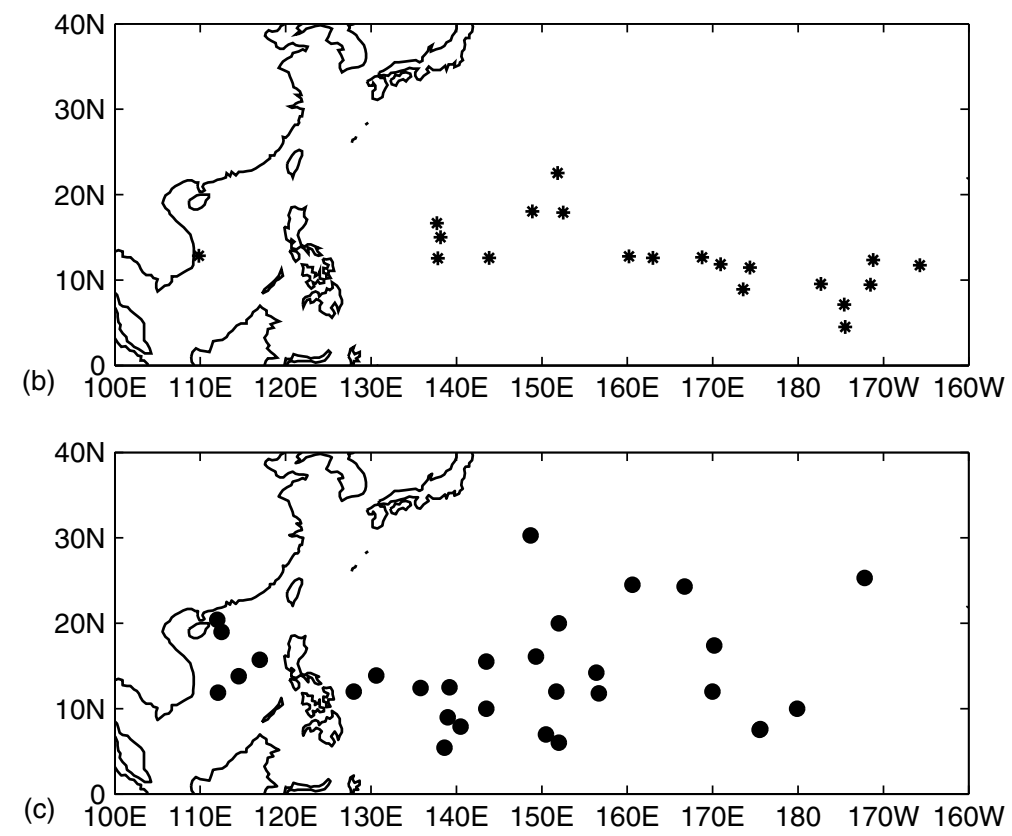

Figure 8. First position of western North Pacific tropical cyclones for June-November 1994 in a single simulation from the (a) RSM, (b) ECHAM4.5 and (c) in observations. The ECHAM ensemble member shown in (b) forces the RSM simulation in (a). 

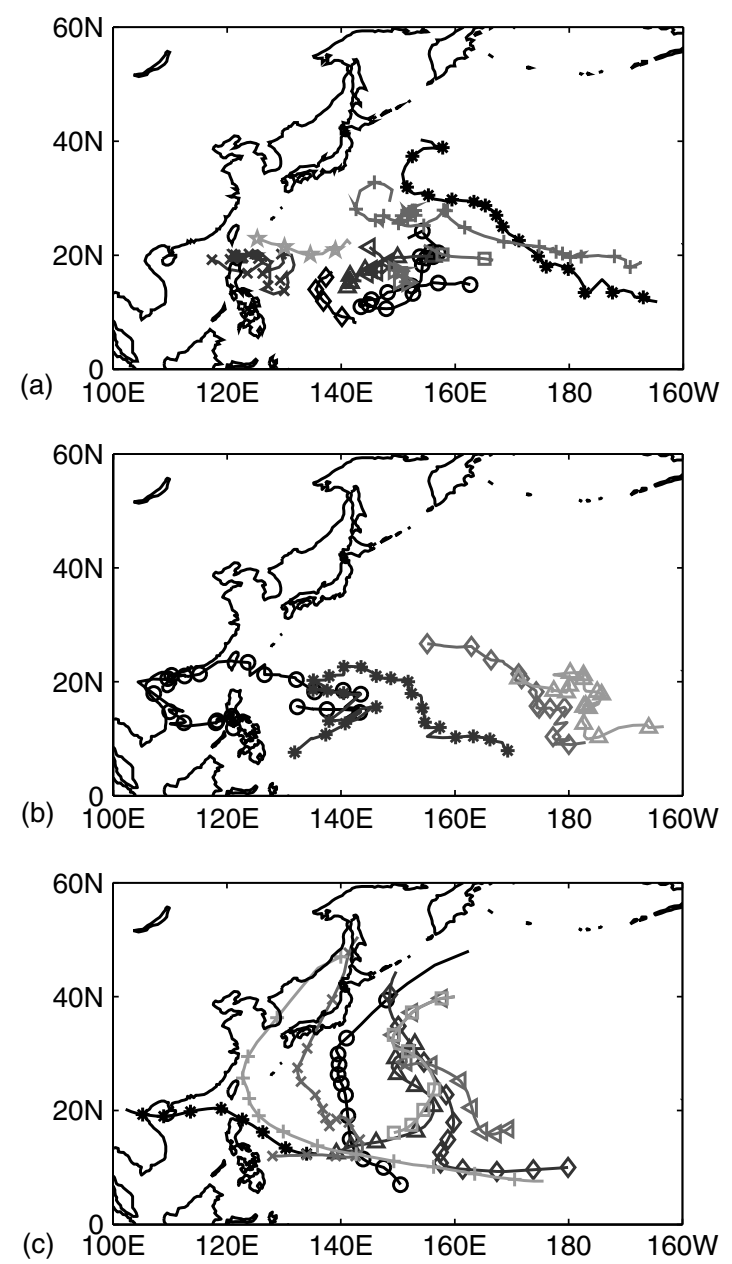

Figure 9. Tracks of western North Pacific tropical cyclones in September of 1994 in one of the ensemble members in the models (a) RSM, (b) ECHAM4.5 and (c) in observations. The ECHAM ensemble member shown in (b) forces the RSM simulation in (a).

Figure 10 shows the tracks density difference between 1994 and 1998. Both models have a higher density of tracks in 1994 than in 1998, as in the observations, as shown by the predominance of yellows and reds. However, while in the observations the maximum of the density difference is in the middle of the basin, both models tend to have an east-west pattern, with a higher density of tracks in 1994 in the east part of the basin and a predominance of tracks in the western part of the basin in 1998. This east-west pattern can also be noted when the tracks density of the observations for each year is examined (not shown), as well as in the statistics of the distributions, but is not obvious from the track density difference pattern. The east-west pattern in the track density is due to the southeast (northwest) shift of TC activity in El Niño (La Niña) events in the western North Pacific (e.g. Chia and Ropelewski, 2002). This shift in the location was reproduced in the RSM and ECHAM4.5 models mostly as an east/west shift in TC activity (Figure 10).

The RSM track density is maximum in locations more similar to the observations than in ECHAM4.5, which has
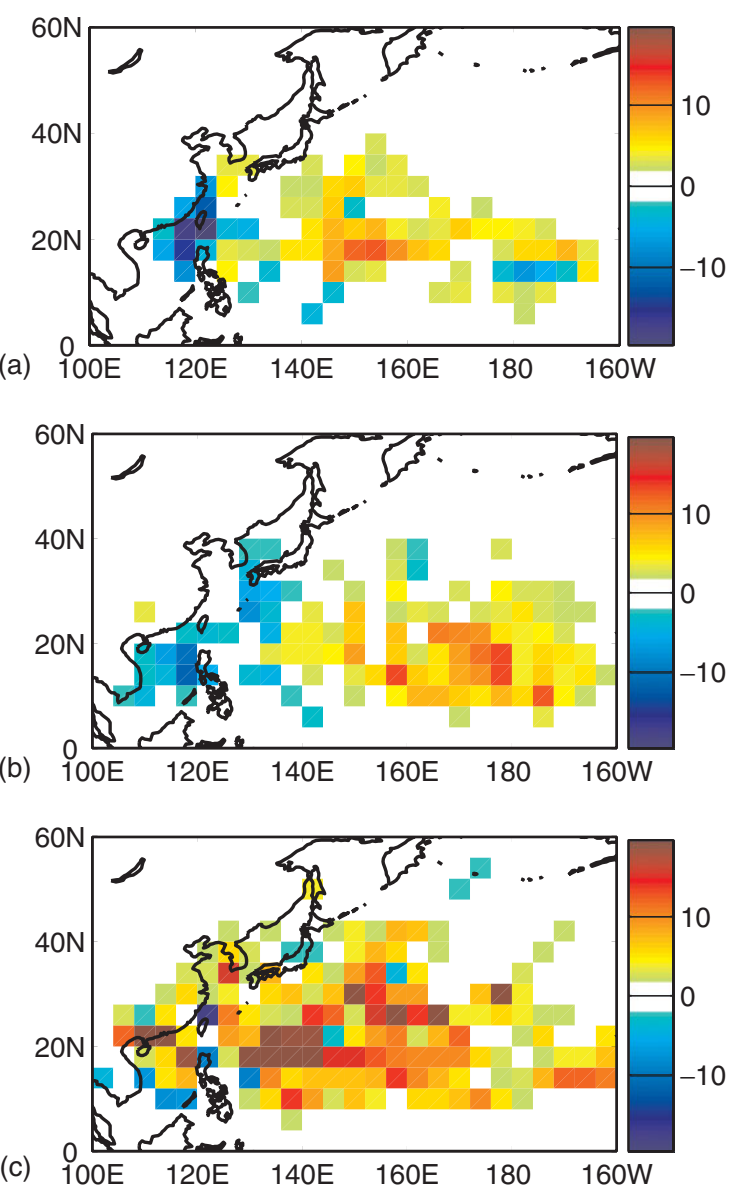

Figure 10. Track density difference of western North Pacific tropical cyclones in JJASON 1994 and 1998 ensemble mean in the models (a) RSM, (b) ECHAM4.5 and (c) in observations.

a known eastward bias (Camargo et al., 2004a, 2005). In the RSM also the tendency of having nonzero track density values near the equator is also not present, while it occurs in the ECHAM4.5, due to the low resolution, as is typical of AGCMs TC activity at this resolution (Camargo et al., 2005).

\subsection{Tropical cyclone intensity}

ACE (Bell et al., 2000) is defined as the sum of the squares of the maximum wind of TCs active in the model at each 6-h interval. In the case of observations, only tropical storms or typhoons were considered, i.e. tropical depressions are not included in the calculation of seasonal ACE.

In both models, the seasonal ACE distribution is shifted to higher values in 1994, with both models having a wider spread among the ensemble members in 1998 (Figure 11(a)). Though both models have essentially the right behavior with lower seasonal ACE in 1998, because of the low resolution of both the ECHAM4.5 and RSM, seasonal ACE values in the basin per season are much smaller than the observed ACE value (Figure 11(b)). The seasonal ACE values of RSM are slightly larger than the case of ECHAM4.5. The models' ACE are too small during the most active months 

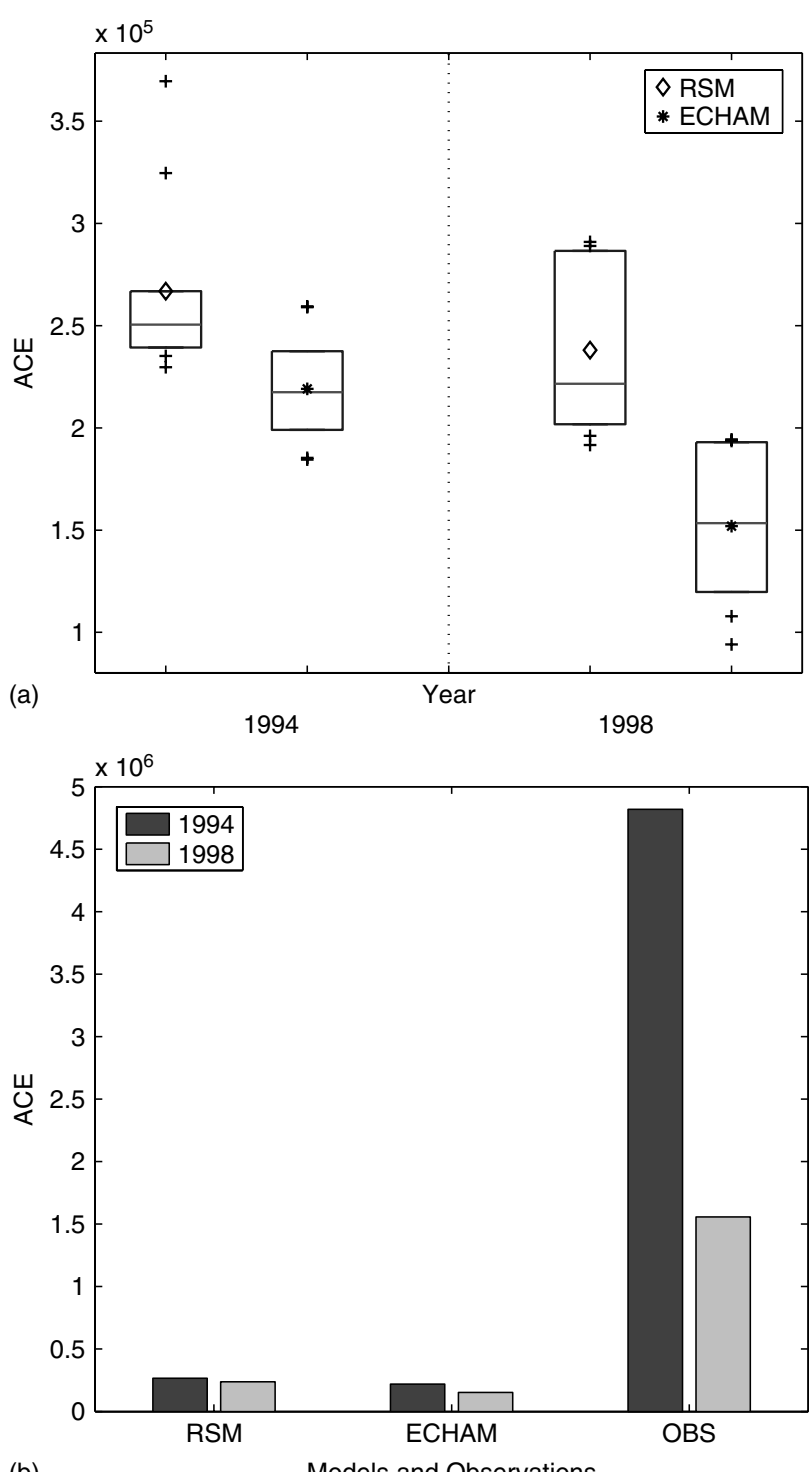

(b)

Models and Observations

Figure 11. (a) Distribution of ACE per season (JJASON) in 1994 and 1998 of the 12 ensemble members of RSM and ECHAM4.5 models. The boxes show the 25th and 75th percentiles, the lines in the boxes mark the median, the asterisks and deltas the mean, and the crosses the values below (above) the 25th (75th) percentiles of the distributions. (b) ACE per season (JJASON) in 1994 and 1998 for the models (median of the ensemble members) and observations.

(July to October), but in the beginning and end of the season the models are comparatively too active, having a much flatter annual cycle than the observations (not shown).

Let us examine the characteristics of the intensity of the TCs in the RSM and ECHAM4.5 in more detail, by examining the distribution of the maximum wind speed and vorticity of all TCs of each model (Figure 12). The peak of the distribution of the RSM TCs wind speed occurs for smaller values than the peak of ECHAM TCs (Figure 12(a)), however, the distribution for RSM has a longer tail. In contrast, the distribution of the maximum vorticity of the TCs (Figure 12(b)) for the RSM is shifted to higher values and has a longer tail compared with ECHAM. Therefore, in terms of

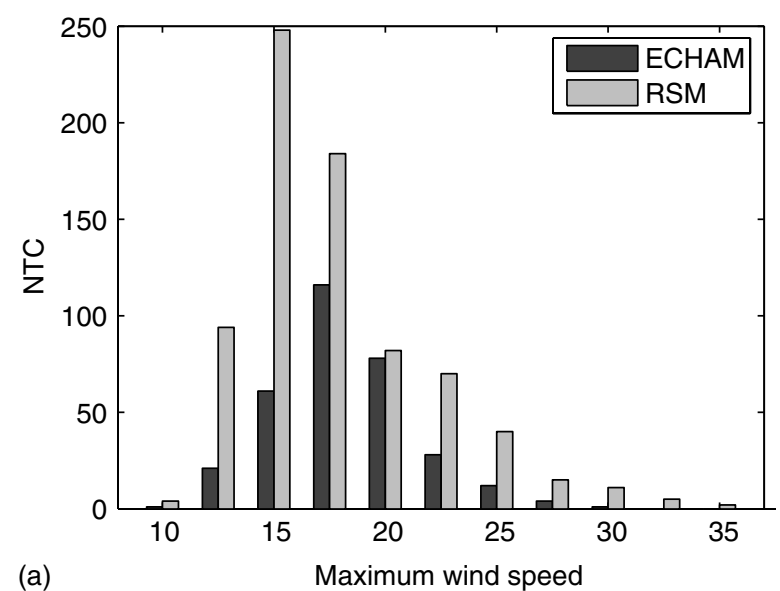

(a)

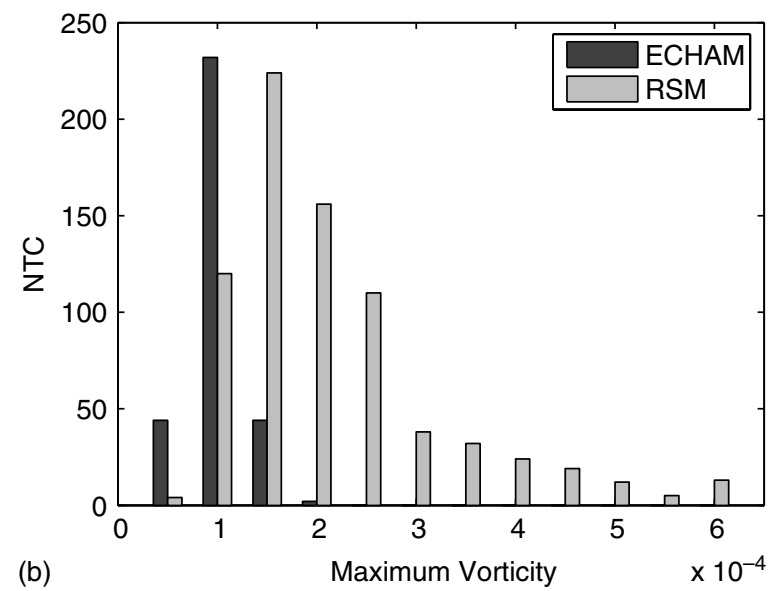

Figure 12. Distributions of (a) maximum wind speed $\left(\mathrm{m} \mathrm{s}^{-1}\right)$ and (b) vorticity $\left(\mathrm{s}^{-1}\right)$ of the RSM and ECHAM4.5 tropical cyclones.

maximum wind speed most of the RSM TCs are weak, though a few of them do manage to intensify. In terms of vorticity, the RSM TCs are more intense than the ECHAM4.5 TCs, which is consistent with the smaller size of TCs in the RSM and not very high values of wind speeds.

\subsection{Tropical cyclone duration}

The lifetime distribution of the TCs in the models and observations is given in Figure 13(a). In AGCMs, the average TC lifetimes are larger than those observed (Camargo et al., 2005), as shown in the case of ECHAM4.5 in Figure 13(a). The RSM lifetimes are much more similar to the observed ones, the downscaling correcting this bias of the AGCMs.

The number of days in which a TC is active in the base on a determined season (or month) is called the number of TC days. In terms of TC days, both models have a bias toward high values, especially in 1998, as shown in Figure 13(b). This high number of TC days is not because of the lifetimes of the RSM TCs, which are very similar to the observed, but rather to the high number of TCs generated by the model. 


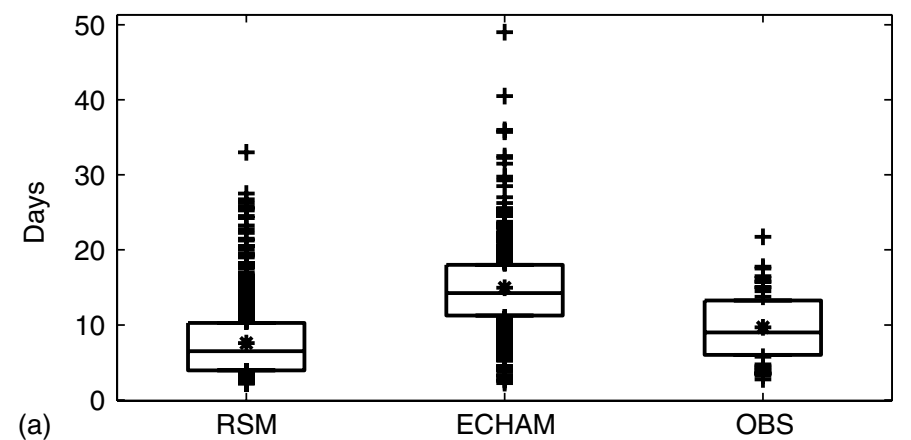

(a)

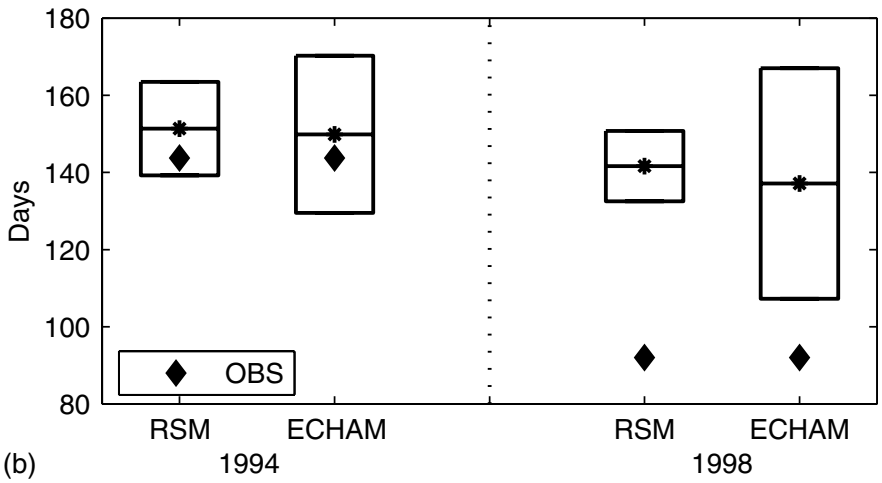

Figure 13. (a) Distributions of all tropical cyclones lifetimes in the RSM and ECHAM4.5 and observations. (b) Distributions of all tropical cyclone days per season in the models and observations in 1994 and 1998.

(a)

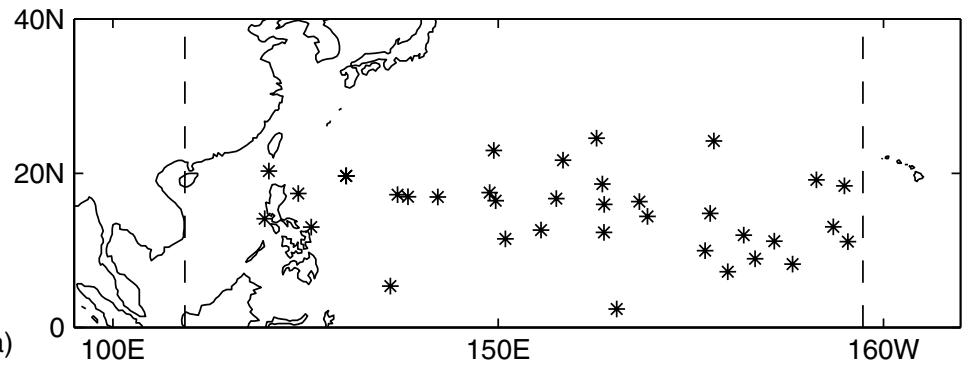

(b)

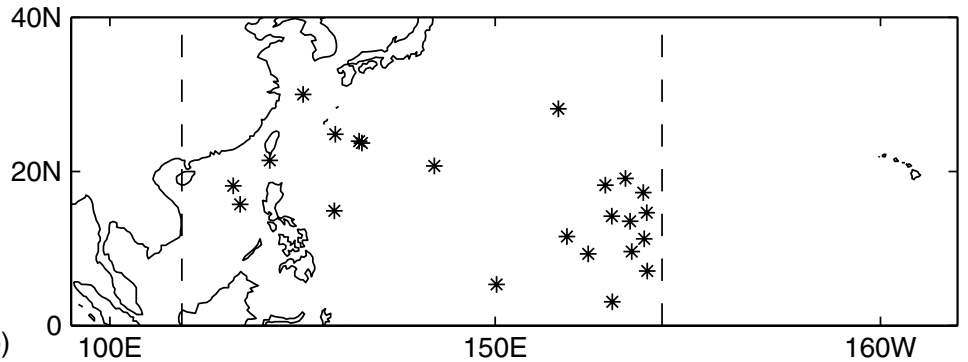

(c)

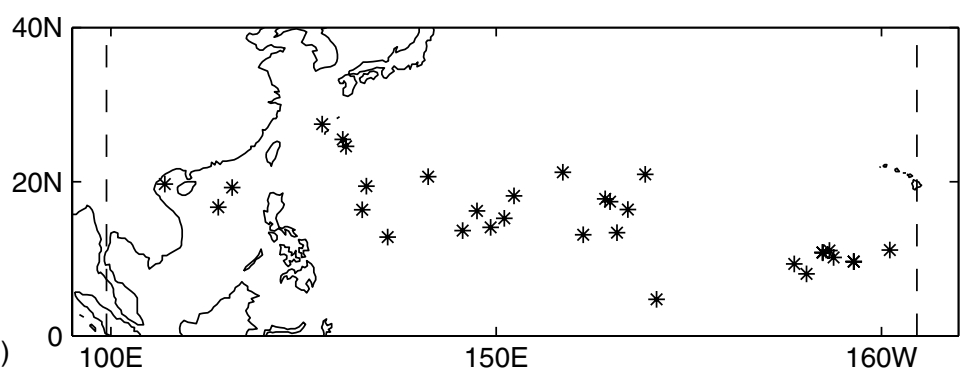

Figure 14. First position locations of RSM model tropical cyclones for the standard (a), small (b) and large (c) domains in JJASO 1994 for one ensemble member. The three RSM simulations were forced by the same ECHAM ensemble member. The dashed lines show the regional model longitudinal boundaries in each case. 


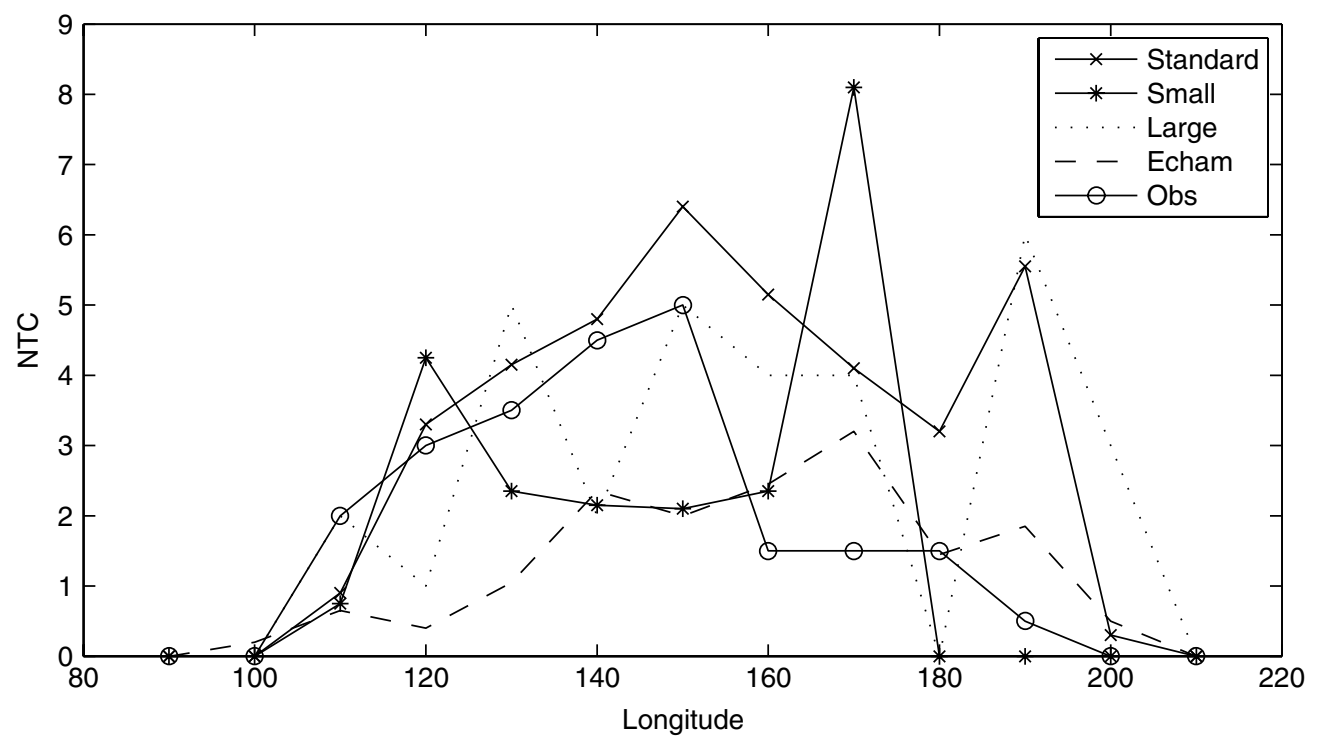

Figure 15. Mean number of tropical cyclones per longitude band in the RSM model (standard, small and large domains), the Echam4.5 model and in observations. In the case of the standard, small, and Echam4.5 models, ten ensemble members and two seasons were used in calculating the mean. The observations values are the mean of the two seasons. In the case of the large domain, it is the total number of genesis per longitude band in the 1994 season (one ensemble member only).

Table III. Boundary domain size of baseline simulations and sensitivity tests simulations with the RSM.

\begin{tabular}{lcccc}
\hline Type & Years & $\begin{array}{c}\text { Ensemble } \\
\text { Members }\end{array}$ & $\begin{array}{c}\text { Longitude } \\
\text { Range }\end{array}$ & $\begin{array}{c}\text { Resolution } \\
(\mathrm{km})\end{array}$ \\
\hline Standard & 1994,1998 & 10 & $109.7^{\circ} \mathrm{E}$ to $162.6^{\circ} \mathrm{W}$ & 50 \\
Small domain & 1994,1998 & 10 & $109.7^{\circ} \mathrm{E}$ to $171.7^{\circ} \mathrm{E}$ & 50 \\
Large domain & 1994 & 1 & $99.4^{\circ} \mathrm{E}$ to $155.4^{\circ} \mathrm{W}$ & 50 \\
\hline
\end{tabular}

\section{SENSITIVITY TESTS}

The regional climate model simulations are affected by domain size and location of the lateral boundaries (Seth and Giorgi, 1998). Landman et al. (2005), showed recently that the simulation of TCs by a regional climate model over the South Indian Ocean is strongly influenced by the position of the eastern boundary of the regional model domain, as many cyclones are advected through that boundary. In that study, it was also shown that the size of the domain also determined the ability of that regional model to simulate TCs tracks and landfall.

In contrast to Landman et al. (2005), a regional spectral model is used here, not a grid point regional model. In a regional spectral model, there is no buffer zone, as the spectral model is a perturbation model and it is forced with the large-scale fields throughout the domain, and not only in the boundaries. However, there are still boundary effects, as these perturbations are defined to be zero at the boundary. In previous studies (Juang and Kanamitsu, 1994; Sun et al., 2006), it was shown that the boundary effects are usually restricted to a very small (five grid points) region around the boundaries.

To evaluate how the results we obtained are dependent on the choice of the model boundary locations and size, we did two separate set of experiments, differing in the domain size and location.
In the first experiment (named 'small domain'), the eastern boundary of the domain was moved westward and the western boundary was kept in the same location; this experiment is named here. In the second experiment (named 'large domain'), the domain was expanded, with western (eastern) boundary shift westward (eastward). The details of these experiments are given in Table III.

In Figure 14 the genesis locations of the model TCs for the three different experiments are shown. The only difference among these experiments is the domain size of the regional model. In the three cases shown, the RSM was forced by the same ECHAM ensemble member in the June-November 1994 period. In the standard (a) and the small domain (b) experiments, there is a high concentration of genesis near the eastern boundary of both domains. The problem being more accentuated in the smaller domain (b). By having a larger domain (c), the genesis locations are spread more evenly. Note also the genesis of a TC west of Hainan island in the large domain (c), which was not possible to occur in the two other domains. In Figure 15, the mean number of TCs per longitude band in each case (including observations and the Echam 4.5 model are shown). One notices that the genesis formation east of the dateline is very rare in observations. Also, it is clear that the ECHAM model has an eastward bias in 


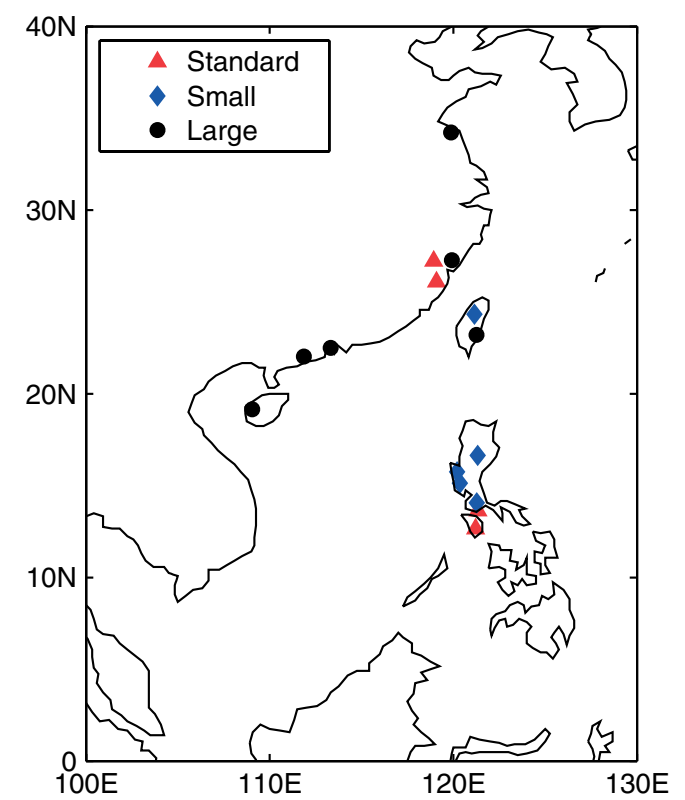

Figure 16. Landfall locations of the RSM model tropical cyclones for the standard, small and large domains, in JJASO 1994 for one ensemble member. The three RSM simulations shown are forced by the same ECHAM simulation.

genesis location (as discussed in Camargo et al. (2005)) and the RSM model forced by the large-scale fields of the ECHAM4.5 has the same eastward bias, accentuated near the regional model boundary. It is important to remember that in Figure 15, ten ensemble members and two seasons were used to calculate the mean in the case of the standard and small RSM domain, as well as for the ECHAM model. In contrast, the large domain uses only one season and ensemble member; and the observation of two seasons, and the curves in these cases are noisier.

In Figure 16, we show the landfall locations for each of the three domains forced by the same ECHAM ensemble member in the June-November period. With the extended domain, a larger number of landfalls occur in the Asian continent, compared with the smaller domains. Therefore, a domain choice with a westward extension would be fundamental for landfall probabilities studies.

\section{CONCLUSIONS}

In this paper, we explored using the RSM regional climate model to improve the TC activity forecasts in AGCMs. To do that, we forced the RSM in two typhoon seasons (June-November) with ten ensemble members of the AGCM. The two typhoon seasons chosen (1994 and 1998) have a high (low) typhoon activity, respectively.

Some of the aspects of the RSM TCs are indeed improved compared to the AGCM, because of the finer horizontal resolution. However, the signal in the difference of the number of TCs in the two seasons is not reproduced in the RSM, while it was present in the AGCM. In contrast, the TC activity in terms of track density and ACE is indeed higher in 1994 than in 1998 in the RSM model.

Therefore, although the RSM does not produce more TCs in 1994 than 1998, in 1994 the TCs last longer and are more intense than in 1998, with an overall higher model TC activity in 1994 than in 1998, as in the observations. Though this result is not very encouraging, one has to keep in mind that only two seasons were analyzed and for a definite answer of the skill of the RSM many more years of simulation would be necessary.

We also discussed the effect of domain choice in our simulations. These sensitivity tests suggest that a larger domain would result in more realistic simulations than in the case of the standard domain used in this study.

Another point to keep in mind is that using a new version of the RSM could, in theory, improve the TC activity in the model. A parameterization of the convectioninduced pressure gradient force (PGF) in convective momentum transport (CMT) was implemented in the new version of RSM. Inclusion of the CMT helps suppress spurious development of TCs. In the parameterization the PGF is assumed to be proportional to the product of the cloud mass flux and vertical wind shear. The new PGF parameterization helps increase hurricane intensity by reducing the vertical momentum exchange, giving rise to a closer comparison to the observations (Han and Pan, 2006).

\section{ACKNOWLEDGEMENTS}

We would like to thank Adam H. Sobel and Michael K. Tippett for comments on this paper, Andrew W. Robertson for valuable discussions, M. Benno Blumenthal for the IRI data library and David G. deWitt for performing the ECHAM4.5 simulations. The authors are grateful for very helpful reviews by Johnny C.L. Chan and an anonymous reviewer. This work was supported by NOAA through a block grant to the International Research Institute for Climate and Society.

\section{NOTES}

1. The ECMWF TCs seasonal forecasts are not public.

2. The 'small domain' experiment was actually our first choice of domain, and ten ensemble realizations of two seasons with this domain were performed. While analyzing the results of this experiment, we decided that a larger domain would be more appropriate and the integrations were then repeated with our standard domain. The 'large domain' experiment was performed with only one ensemble member in one season only, owing to computational time constraints.

\section{REFERENCES}

Bell GD, Halpert MS, Schnell RC, Higgins RW, Lawrimore J, Kousky VE, Tinker R, Thiaw W, Chelliah M, Artusa A. 2000. Climate assessment for 1999. Bulletin of the American Meteorological Society 81: S1-S50.

Bengtsson L, Böttger H, Kanamitsu M. 1982. Simulation of hurricanetype vortices in a general circulation model. Tellus 34: 440-457.

Bengtsson L, Botzet M, Esch M. 1995. Hurricane-type vortices in a general circulation model. Tellus A 47: 175-196. 
Bengtsson L, Botzet M, Esch M. 1996. Will greenhouse gas-induced warming over the next 50 years lead to higher frequency and greater intensity of hurricanes? Tellus A 48: 57-73.

Briegel LM, Frank WM. 1997. Large-scale influences on tropical cyclogenesis in the western North Pacific. Monthly Weather Review 125: $1397-1413$.

Broccoli AJ, Manabe S. 1990. Can existing climate models be used to study anthropogenic changes in tropical cyclone climate? Geophysical Research Letters 17: 1917-1920.

Camargo SJ, Zebiak SE. 2002. Improving the detection and tracking of tropical storms in atmospheric general circulation models. Weather and Forecasting 17: 1152-1162.

Camargo SJ, Sobel AH. 2004. Formation of tropical storms in an atmospheric general circulation model. Tellus A 56: 56-67.

Camargo SJ, Sobel AH. 2005. Western North Pacific tropical cyclone intensity and ENSO. Journal of Climate 18: 2996-3006.

Camargo SJ, Barnston AG, Zebiak SE. 2004a. Properties of tropical cyclones in atmospheric general circulation models. IRI Technical Report 04-02. International Research Institute for Climate Prediction: Palisades; 72.

Camargo SJ, Robertson AW, Gaffney SJ, Smyth P. 2004b. Cluster analysis of western North Pacific tropical cyclone tracks. Proceedings of the 26th Conference on Hurricanes and Tropical Meteorology. American Meteorological Society: Miami, FL; $250-251$.

Camargo SJ, Barnston AG, Zebiak SE. 2005. A statistical assessment of tropical cyclones in atmospheric general circulation models. Tellus A 57: 589-604.

Castro CL, Pielke RA Sr, Leoncini G. 2005. Dynamical downscaling: assessment of value retained and added using the regional atmospheric modeling system (RAMS). Journal of Geophysical Research 110: D05108, doi: 10.1029/2004JD004721.

Chan JCL. 1985. Tropical cyclone activity in the northwest pacific in relation to El Niño/southern oscillation phenomenon. Monthly Weather Review 113: 599-606.

Chan JCL. 2005. Interannual and interdecadal variations of tropical cyclone activity over the western North Pacific. Meteorology and Atmospheric Physics 89: 143-152, doi:10.1007/s00703-005-0126-y.

Chan JCL, Liu KS. 2004. Global warming and western North Pacific typhoon activity from an observational perspective. Journal of Climate 17: 4590-4602.

Chan JCL, Shi JE, Lam CM. 1998. Seasonal forecasting of tropical cyclone activity over the western North Pacific and the South China Sea. Weather and Forecasting 13: 997-1004.

Chan JCL, Shi JE, Liu KS. 2001. Improvements in the seasonal forecasting of tropical cyclone activity over the western North Pacific. Weather and Forecasting 16: 491-498.

Chan JCL, Liu YM, Chow KC, Ding YH, Lau WKM, Chan KL. 2004. Design of a regional climate model for the simulation of South China summer monsoon rainfall. Journal of the Meteorological Society of Japan 78: $367-380$.

Cheung KKW, Elsberry RL. 2002. Tropical cyclone formations over the western North Pacific in the navy operational global atmospheric prediction system forecasts. Weather and Forecasting 17: 800-820.

Chia HH, Ropelewski CF. 2002. The interannual variability in the genesis location of tropical cyclones in the northwest pacific. Journal of Climate 15: 2934-2944.

Druyan LM, Lonergan P, Eichler T. 1999. A GCM investigation of global warming impacts relevant to tropical cyclone genesis. International Journal of Climatology 19: 607-617.

Fiorino M. 2002. Analysis and forecasts of tropical cyclones in the ECMWF 40-Year reanalysis (ERA-40). Proceedings of the 25th Conference on Hurricanes and Tropical Meteorology. American Meteorological Society: San Diego, CA; 261-264.

Fu C, Wang S, Xiong Z, Gutowski WJ, McGregor DKLJL, Sato Y, Kato H, Kim JW, Suh MS. 2005. Regional climate model intercomparison project for Asia. Bulletin of the American Meteorological Society 86: 257-266.

Gray WM. 1979. Hurricanes: their formation, structure and likely role in the tropical circulation. Meteorology Over the Tropical Oceans. Royal Meteorological Society; 155-218.

Haarsma RJ, Mitchell JFB, Senior CA. 1993. Tropical disturbances in a GCM. Climate Dynamics 8: 247-257.

Han J, Pan HL. 2006. Sensitivity of hurricane intensity forecast to convective momentum transport parameterization. Monthly Weather Review 134: 664-674.

Holland GJ. 1995. Scale interaction in the western pacific monsoon. Meteorology and Atmospheric Physics 56: 57-79.
IRI. 2006. IRI (International Research Institute for Climate Prediction) Tropical Cyclone Activity Experimental Dynamical Forecasts, available on line at: http://iri.columbia.edu/forecast/tc_fcst.

JTWC. 2006. JTWC (Joint Typhoon Warning Center) best track dataset, available online at https://metoc.npmoc.navy.mil/jtwc/best_ tracks/.

Juang HMH, Kanamitsu M. 1994. The NMC nested regional spectral model. Monthly Weather Review 122: 3-26.

Juang HMH, Hong SY. 2001. Sensitivity of the NCEP regional spectral model to domain size and nesting strategy. Monthly Weather Review 129: 2904-2922

Juang HMH, Hong SY, Kanamitsu M. 1997. The NCEP regional spectral model: an update. Bulletin of the American Meteorological Society 78: $2125-2143$.

Knutson TR, Tuleya RE. 2004. Impact of $\mathrm{CO}_{2}$-induced warming on simulated hurricane intensity and precipitation: sensitivity to choice of climate model and convective parametrization. Journal of Climate 17: 3477-3495.

Kobayashi C, Sugi M. 2004. Impact of horizontal resolution on the simulation of the Asian summer monsoon and tropical cyclones in the JMA global model. Climate Dynamics 93: 165-176.

Lander MA. 1996. Specific tropical cyclone tracks and unusual tropical cyclone motions associated with a reverse-oriented monsoon trough in the western North Pacific. Weather and Forecasting 11: 170-186.

Landman WA, Seth A, Camargo SJ. 2005. The effect of regional climate model domain choice on the simulation of tropical cyclonelike vortices in the southwestern Indian Ocean. Journal of Climate 18: $1263-1274$.

Liu KS, Chan JCL. 2003. Climatological characteristics and seasonal forecasting of tropical cyclones making landfall along the South China coast. Monthly Weather Review 131: 1650-1662.

Liu YM, Chan JCL, Chow KC, Ding YH. 2006. Ten-year climatology of summer monsoon over South China and its surroundings simulated from a regional climate model. International Journal of Climatology 26: 141-157.

Manabe S, Holloway JL, Stone HM. 1970. Tropical circulation in a time-integration of a global model of the atmosphere. Journal of the Atmospheric Sciences 27: 580-613.

Matsuura T, Yumoto M, Iizuka S. 2003. A mechanism of interdecadal variability of tropical cyclone activity over the western North Pacific. Climate Dynamics 21: 105-117.

Matsuura T, Yumoto M, Iizuka S, Kawamura R. 1999. Typhoon and ENSO simulation using a high-resolution coupled GCM. Geophysical Research Letters 26: 1755-1758.

McBride JL. 1981. Observational analysis of tropical cyclone formation. Part I: Basic description of data sets. Journal of the Atmospheric Sciences 38: 1117-1131.

Nguyen KC, Walsh KJE. 2001. Interannual, decadal and transient greenhouse simulation of tropical cyclone-like vortices in a regional climate model of the South Pacific. Journal of Climate 14: 3043-3054.

Pan YH. 1982. The effect of the thermal state of equatorial eastern Pacific on the frequency of typhoon over the western pacific. Acta Meteorologica Sinica 40: 24-34, in Chinese with English abstract.

Rauscher SA, Seth A, Qian J-H, Camargo SJ, 2006. Domain choice in an experimental nested modeling prediction system for South America. Theoretical and Applied Climatology 86: 229-246, Doi: 10.1007/s00704-006-0206-z.

Reynolds RW, Smith TM. 1994. Improved global sea surface temperature analyses using optimum interpolation. Journal of Climate 7: 929-948.

Reynolds RW, Rayner NA, Smith TM, Stokes DC, Wang W. 2002. An improved in situ and satellite SST analysis for climate. Journal of Climate 15: 1609-1625.

Ritchie ER, Holland GJ. 1999. Large-scale patterns associated with tropical cyclogenesis in the western Pacific. Monthly Weather Review 127: 2027-2043.

Roeckner E, Arpe K, Bengtsson L, Christoph M, Claussen M, Dümenil L, Esch M, Giorgetta M, Schlese U, Schulzweida U. 1996. The atmospheric general circulation model ECHAM-4: model description and simulation of present-day climate. Tech. Rep. 218. Max-Planck Institute for Meteorology: Hamburg; 90.

Royer JF, Chauvin F, Timbal B, Araspin P, Grimal D. 1998. A GCM study of the impact of greenhouse gas increase on the frequency of occurrence of tropical cyclones. Climatic Change 38: 307-343.

Ryan BF, Watterson IG, Evans JL. 1992. Tropical cyclone frequencies inferred from gray's yearly genesis parameter: validation of GCM tropical climate. Geophysical Research Letters 19: 1831-1834. 
Serrano E. 1997. Tropical cyclones. ECMWF Re-Analysis Project Report Series 5. European Centre for Medium-Range Weather Forecasts: Reading; 30

Seth A, Giorgi F. 1998. The effects of domain choice in summer precipitation simulation and sensitivity in a regional climate model. Journal of Climate 11: 2698-2712.

Sobel AH, Bretherton CS. 1999. Development of synoptic-scale disturbances over summertime tropical northwest pacific. Journal of the Atmospheric Sciences 56: 3106-3127.

Sugi M, Noda A, Sato N. 2002. Influence of global warming on tropical cyclone climatology: an experiment with the JMA global model. Journal of the Meteorological Society of Japan 80: 249-272.

Sun L, Moncunill DF, Li H, Moura AD, Filho FAS. 2005. Climate downscaling over Nordeste Brazil using NCEP RSM97. Journal of Climate 18: 551-567.

Sun L, Moncunill DF, Li H, Moura AD, Filho FAS, Zebiak SE. 2006. An operational dynamical downscaling prediction system for Nordeste Brazil and the 2002-04 real-time forecast evaluation. Journal of Climate 19: 1990-2007.

TSR. 2006. Tropical Storm Risk, available online at http://tropical stormrisk.com/.

Tsutsui JI, Kasahara A. 1996. Simulated tropical cyclones using the national center for atmospheric research community climate model. Journal of Geophysical Research 101: 15013-15032.

Uppala SM, Kållberg PW, Simmons AJ, Andrae U, da Costa Bechtold V, Fiorino M, Gibson JK, Haseler J, Hernandez A, Kelly GA, Li X, Onogi K, Saarinen S, Sokka N, Allan RP, Andersson E, Arpe K, Balmaseda MA, Beljaars ACM, van de Berg L, Bidlot J, Bormann N, Caires S, Chevallier F, Dethof A, Dragosavac M, Fisher M, Fuentes M, Hagemann S, Holm E, Hoskins BJ, Isaksen L, Janssen PAEM, Jenne R, McNally AP, Mahfouf JF, Morcrette JJ, Rayner NA, Saunders RW, Simon P, Sterl A, Trenberth KE, Untch A, Vasiljevic D, Viterbo P, Woollen J. 2005. The ERA-40 re-analysis. Quarterly Journal of the Royal Meteorological Society 131: 2961-3012, doi:10.1256/qj.04.176.

Vitart F. 2006. Seasonal forecasting of tropical storm frequency using a multi-model ensemble. Quarterly Journal of the Royal Meteorological Society 132: 647-666, doi:10.1256/qj.05.65.
Vitart F, Anderson JL. 2001a. Sensitivity of Atlantic tropical storm frequency to ENSO and interdecadal variability of SSTs in an ensemble of AGCM integrations. Journal of Climate 14: 533-545.

Vitart FD, Stockdale TN. 2001b. Seasonal forecasting of tropical storms using coupled GCM integrations. Monthly Weather Review 129: $2521-2537$.

Vitart F, Anderson JL, Stern WF. 1997. Simulation of interannual variability of tropical storm frequency in an ensemble of GCM integrations. Journal of Climate 10: 745-760.

Vitart F, Anderson JL, Stern WF. 1999. Impact of large-scale circulation on tropical storm frequency, intensity and location, simulated by an ensemble of GCM integrations. Journal of Climate 12: $3237-3254$

Vitart F, Anderson D, Stockdale T. 2003. Seasonal forecasting of tropical cyclone landfall over Mozambique. Journal of Climate 16: $3932-3945$.

Walsh K. 1997. Objective detection of tropical cyclones in highresolution analyses. Monthly Weather Review 125: 1767-1779.

Walsh K. 2004. Tropical cyclones and climate change: unresolved issues. Climate Research 27: 77-83.

Walsh KJE, Ryan BF. 2000. Tropical cyclone intensity increase near Australia as a result of climate change. Journal of Climate 13: 3029-3036.

Walsh KJE, Syktus J. 2003. Simulations of observed interannual variability of tropical cyclone formation in East of Australia. Atmospheric Science Letters 4: 28-40.

Walsh KJE, Nguyen KC, McGregor JL. 2004. Fine-resolution regional climate model simulations of the impact of climate change on tropical cyclones near Australia. Climate Dynamics 22: 47-56.

Wang B, Chan JCL. 2002. How strong ENSO events affect tropical storm activity over the western North Pacific. Journal of Climate 15: $1643-1658$

Wu G, Lau NC. 1992. A GCM simulation of the relationship between tropical storm formation and ENSO. Monthly Weather Review 120: 958-977.

Yumoto M, Matsuura T, Iizuka S. 2003. Interdecadal variability of tropical cyclone frequency over the western North Pacific in a high-resolution atmosphere-ocean coupled GCM. Journal of the Meteorological Society of Japan 81: 1069-1086. 